\title{
The State of Health in Pakistan: An Overview
}

\section{Uzma Afzal* and Anam Yusuf*}

\begin{abstract}
Although the Millennium Development Goals provide countries with wellrounded objectives for achieving human development over a period of 25 years, Pakistan is not on track to achieving the health-related goals. With the eighth highest newborn death rate in the world, in 2001-07 one in every ten children born in Pakistan died before reaching the age of five. Similarly, women have a 1 in 80 chance of dying of maternal health causes during reproductive life. Compared to other South Asian countries, Pakistan currently lags behind in immunization coverage, contraceptive use, and infant and child mortality rates. Expenditure as a percentage of private expenditure on health is about 98 percent, positioning Pakistan among those countries with the highest share of out-of-pocket payments relative to total health expenditure (World Health Organization, 2009). Pakistan is also going through an epidemiological transition where it faces the double burden of communicable diseases combined with maternal and perinatal conditions, as well as chronic, noninfectious diseases. The landscape of public health service delivery presents an uneven distribution of resources between rural and urban areas: The rural poor are at a clear disadvantage in terms of primary and tertiary health services, and also fail to benefit fully from public programs such as the immunization of children. The poor state of public facilities overall has contributed to the diminished role of public health facilities, while the private sector's role in the provision of service delivery has increased enormously. Following the $18^{\text {th }}$ Amendment to the Constitution, the health sector has been devolved to the provinces, but the distribution of responsibilities and sources of revenue generation between the tiers remains unclear. A multipronged national health policy is needed that tackles the abysmal child and maternal health indicators, and reduces the burden of disease. Moreover, it is imperative to improve the provision of primary and tertiary healthcare with a strong monitoring system in place.
\end{abstract}

Keywords: Millenium Development Goals, public health, Pakistan.

JEL classification: I18.

\footnotetext{
* Senior Teaching and Research Fellow, Center for Research in Economics and Business (CREB), Lahore School of Economics, Pakistan.

** Research Fellow, Graduate Institute of Development Studies (GIDS), Lahore School of Economics, Pakistan.
} 


\section{Introduction}

The Millennium Development Goals (MDGs) provide timebounded objectives to overcome extreme poverty and provide the basic human rights to health, education, and security that were pledged in the Universal Declaration of Human Rights and United Nations Millennium Declaration (Millennium Project, 2006). Two years short of the deadline in 2015, it is useful to see how Pakistan has performed in the health-related goals that were set in 2000. Health outcomes are useful in gauging a country's health performance over past decades and in conducting crosscountry comparisons.

Pakistan is not on track to achieving most health-related MDGs. While there has been an improvement in the education sector, health remains on the periphery of the development landscape. With the eighth highest newborn death rate in the world ("Pakistan has the 8th highest," 2010), one in every ten children born in Pakistan during 2001-07 died before reaching the age of five years. Women have a 1 in 80 chance of dying of maternal health causes during their reproductive life (World Bank, 2010). Pakistan thus faces a daunting challenge in improving health outcomes for children and adults alike.

In order to achieve substantial improvements in the health sector, it is imperative to formulate a well-rounded health policy that focuses not only on short-term health outcomes but also on improving the long-term health status of the population at large. Given the current level of government expenditure on health, an improvement in this sector seems unlikely. The quality of public health services has seen a downturn over the last few decades, and the rising population is increasing pressure on state institutions. This has allowed the private sector to bridge the gap between rising demand and public provision of healthcare. The private sector's role in the provision of service delivery has increased enormously. The poor state of public facilities overall has contributed to the diminished role of public health facilities. Out-of-pocket expenditure as a percentage of private expenditure on health is about 98 percent, positioning Pakistan among those countries with the highest share of out-of-pocket payments relative to total health expenditure (World Health Organization, 2009).

Pakistan is going through an epidemiological transition where it faces the double burden of communicable diseases combined with maternal and perinatal conditions, and chronic, noninfectious diseases. The landscape of public health service delivery presents an uneven distribution of resources between rural and urban areas. The rural poor are at a clear 
disadvantage in terms of primary and tertiary health services. They also fail to benefit fully from public programs such as the immunization of children. Following the $18^{\text {th }}$ Amendment to the Constitution, the health sector has been devolved to the provinces, but the distribution of responsibilities and sources of revenue generation between the tiers remains unclear.

\section{Where We Stand: The State of Health}

Although life expectancy, health, and living standards have improved in the last few decades, this growth has not been uniform across countries, and even within countries there exist stark disparities in health outcomes. South Asia has the greatest concentration of malnourished people in the world, where one in every five persons is malnourished or suffers micronutrient deficiencies such as Vitamin A and iron. Estimates suggest that South Asian countries lose about 1 percent of their GDP due to such deficiencies (Pakistan Poverty Alleviation Fund, 2010).

\subsection{Pakistan's Overall State of Health}

Pakistan is a signatory to the United Nations mandate of the MDGs, which are to be attained by 2015. While there have been successes in some areas, the country has not fared well in health-related goals. Currently, it has the highest mortality rates for children and women in South Asia, given which, it will fail to meet MDGs 4, 5, and 6 (on child mortality, maternal health, and combating HIV/AIDS, malaria, and other diseases, respectively). For Pakistan to meet the MDGs, the infant mortality rate should decline to 40 deaths per 1,000 live births and the under-five mortality rate should be no more than 52 deaths per 1,000 live births. Maternal mortality, on the other hand, should decline by almost 50 percent of its current level (140 per 100,000) by 2015 (Khan, 2013).

Estimates indicate that about 38 percent of under-five children are underweight while 12 percent are severely underweight (Khan, 2012). Children represent the most vulnerable group of society, and have not benefited much from previous growth episodes and social development. Countries such as Nepal and Bangladesh have achieved greater progress in their child mortality rates despite similar or worse economic performance (see Table 1).

Maternal mortality, despite being difficult to measure, is alarmingly high. Much of this stems from the low incidence of skilled birth attendance 
and high fertility rates. What is more alarming is that the rate of skilled birth attendance-a proxy for maternal mortality - has actually declined from 48 percent in 2004-06 to 41 percent in 2008/09 (Pakistan, Planning Commission, 2010). The situation is even worse in rural areas where the maternal mortality rate is almost double that of urban areas: 319 per 100,000 in rural areas and 175 per 100,000 in urban areas (Pakistan, Planning Commission, 2010).

Table 1: Health indicators for South Asia

\begin{tabular}{|c|c|c|c|c|c|c|c|c|c|c|}
\hline \multirow[b]{2}{*}{ Health indicators } & \multicolumn{2}{|c|}{ Pakistan } & \multicolumn{2}{|c|}{ Bangladesh } & \multicolumn{2}{|c|}{ India } & \multicolumn{2}{|c|}{ Sri Lanka } & \multicolumn{2}{|c|}{ Nepal } \\
\hline & 1990 & 2010 & 1990 & 2010 & 1990 & 2010 & 1990 & 2010 & 1990 & 2010 \\
\hline $\begin{array}{l}\text { Infant mortality rate (per } 1,000 \\
\text { live births) }\end{array}$ & 95 & 60 & 97 & 39 & 81 & 49 & 24 & 11 & 94 & 41 \\
\hline $\begin{array}{l}\text { Maternal mortality rate (per } \\
100,000 \text { live births) }\end{array}$ & 490 & 260 & 800 & 240 & 600 & 200 & 85 & 35 & 770 & 170 \\
\hline $\begin{array}{l}\text { Under-five mortality rate (per } \\
1,000 \text { live births) }\end{array}$ & 122 & 74 & 139 & 49 & 114 & 63 & 29 & 13 & 135 & 50 \\
\hline $\begin{array}{l}\text { Immunization }(\mathrm{DPT})^{*} \text { among } 1 \text { - } \\
\text { year-olds }(\%)\end{array}$ & 54 & 86 & 69 & 95 & 70 & 72 & 86 & 99 & 43 & 82 \\
\hline $\begin{array}{l}\text { Immunization (measles) among } \\
\text { 1-year-olds (\%) }\end{array}$ & 50 & 82 & 65 & 94 & 56 & 74 & 88 & 99 & 57 & 86 \\
\hline $\begin{array}{l}\text { Total fertility rate (births per } \\
\text { woman) }\end{array}$ & - & 3.4 & - & 2.2 & - & 2.6 & - & 2.3 & - & 2.7 \\
\hline Life expectancy at birth (years) & - & 65.2 & - & 68.6 & - & 65.1 & - & 74.7 & - & 68.4 \\
\hline
\end{tabular}

Source: World Health Organization (2013).

\subsection{Burden of Disease}

Pakistan is going through an epidemiological transition that subjects it to a "double" burden of disease. Communicable diseases combined with maternal and perinatal conditions account for more than 50 percent of the burden. Diseases such as lower respiratory tract infections, diarrheal diseases, measles, and whooping cough (pertussis) account for about a third of the years of life lost, but can be controlled by low-cost interventions such as vaccinations, simple treatments, and hand washing. These account for much of the current burden of disease. The second burden is that of chronic, noninfectious diseases (World Bank, 2010). Figure 1 highlights the total burden of disease in Pakistan. 
Figure 1: Burden of disease in Pakistan

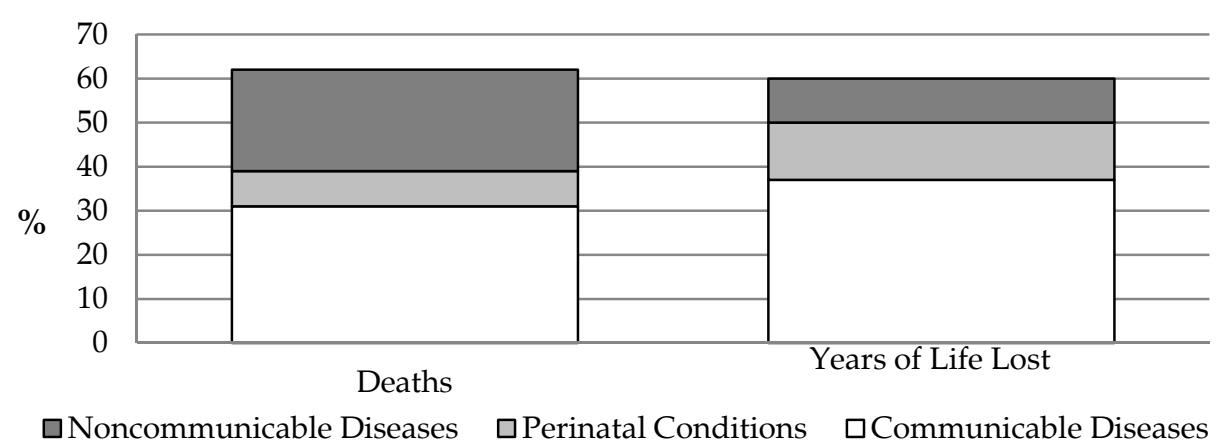

Source: World Health Statistics, 2006.

Hyder and Morrow (2000) look at noncommunicable diseases and find that hypertension, chronic liver disease, and heart disease are among the top ten causes of loss of healthy life years. Coronary artery disease and diabetes are also prevalent, with around 30 percent of the adult population suffering from the former and 7.1 percent from the latter-Pakistan is one of the top few countries in the world prone to the prevalence of diabetes. It is imperative to acknowledge the presence of such high burdens of chronic disease so that the healthcare system can respond to these conditions actively. Unfortunately, there has been little methodical effort to curtail the risk of noncommunicable diseases: for example, despite the high levels of heart disease in Pakistan, neither the public nor the private sector has undertaken any active antismoking campaigns.

In 2004, the Ministry of Health (Government of Pakistan), the World Health Organization (WHO), and Heartfile (a nongovernment organization [NGO]) collectively drafted the National Action Plan for Noncommunicable Disease Prevention, Control, and Health Promotion in Pakistan. The plan incorporated the control and prevention of cardiovascular disease as the basic premise of an inclusive noncommunicable disease prevention effort. The process of surveillance and implementation was started and by October 2007, the action plan's first phase had achieved a number of targets. Such measures have brought issues of disease and their possible prevention into the limelight for policymakers, donors, and the private sector to take effective steps for thorough implementation.

Using data from the Pakistan Demographic Survey for 1997, Hyder, Wali, Ghaffar, Masud, and Hill (2005) measure the burden of premature 
mortality in Pakistan. They note that women experience a greater overall burden of disease than men, owing to reproductive and maternal health issues. Figure 1 also shows that a considerable number of years of life are lost due to poor perinatal conditions.

\section{Landscape of Public Health Service Delivery}

Assessing the performance of the public health service in Pakistan is critical. Despite optimistic claims by Khan (2012) pertaining to improved services, the picture is not too promising. The situation is even more worrying when we look at differences in service provision and utilization among rural areas. They are at a clear disadvantage in terms of the use of primary and tertiary health services. Additionally, the rural poor are marked by substantially lower use of services than the urban poor.

While the coverage of services in rural Punjab and Khyber Pakhtunkhwa (KP) has increased over time, the gap between rural and urban use of health facilities remains stubborn in Sindh and Balochistan (World Bank, 2010). Taking the example of full immunization rates (record and recall) in 2010/11, there is about 79 and 77 percent coverage in rural Punjab and KP, but only 67 and 45 percent in Sindh and Balochistan, respectively (Pakistan Bureau of Statistics, 2010).

There are also large variations between districts within a province. Let us consider the case of rural and urban Punjab with regard to antenatal coverage in the top five and bottom five districts (see Table 2). The province's total estimated antenatal coverage is 68 percent. In the urban areas, 79 percent of expectant mothers have access to antenatal care, but the corresponding figure for the rural areas is just over 60 percent (Punjab, Planning and Development Department, \& United Nations Development Programme, 2011). Individual districts tell a similar story.

Table 2: Coverage of antenatal care in Punjab

\begin{tabular}{|c|c|c|c|c|c|c|c|c|c|}
\hline & \multicolumn{4}{|c|}{ Top five districts } & & \multicolumn{4}{|c|}{ Bottom five districts } \\
\hline & District & Total & Urban & Rural & & District & Total & Urban & Rural \\
\hline 1 & $\begin{array}{l}\text { Mandi } \\
\text { Bahauddin }\end{array}$ & 88 & 86 & 88 & 1 & Muzaffargarh & 55 & 67 & 54 \\
\hline 2 & Rawalpindi & 86 & 85 & 88 & 2 & Rajanpur & 54 & 75 & 52 \\
\hline 3 & Jhelum & 85 & 90 & 82 & 3 & Hafizabad & 50 & 52 & 49 \\
\hline 4 & Lahore & 82 & 85 & 68 & 4 & Bhakkar & 48 & 57 & 47 \\
\hline 5 & Gujrat & 81 & 77 & 82 & 5 & Narowal & 35 & 41 & 34 \\
\hline
\end{tabular}

Source: Punjab Millennium Development Goals Report (2011); data from Multiple Indicator Cluster Survey, 2011. 
We can further assess the performance of public health services through the recent measles outbreak in parts of Sindh and Punjab. A striking number of first-level healthcare facilities were found to be in poor condition and mostly ill equipped. Medicines, especially mumps, measles, and rubella (MMR) vaccination shots, were in drastically short supply at many public healthcare facilities. WHO reported the death of 300 children from measles in December 2012 alone ("Healthcare: The measles muddle," 2013). A dearth of trained health workers was also reported. Staff absenteeism, a serious problem in public healthcare delivery, has also led to dissatisfaction with government health services, especially among the most vulnerable in Pakistan.

This crisis not only reflects the gaps in the public healthcare system, it also addresses the question as to why the private healthcare option is in more demand than public healthcare services. The private sector is now the leading source of outpatient consultations and maternal and child health services, even though the high cost of private healthcare does not explain the use of such an option (World Bank, 2010).

We now analyze three important healthcare programs in Pakistan to underline specific gaps in public health services. Even though there has been a noteworthy increase in national health programs in the last two decades, which has had a positive impact on the healthcare system, their contribution could be strengthened.

Since its initiation in 1978, Pakistan's Expanded Program on Immunization (EPI) has aimed to significantly improve child and maternal health through immunization against tuberculosis (TB), measles, tetanus, diphtheria, pertussis, hepatitis B, and poliomyelitis. However, many targets, such as the elimination of polio and measles, have still not been met and WHO figures paint a dismal picture of the situation. Unfortunately, Pakistan is observed to have reported more cases of polio in 2011 than any other country in the world. Although the number of polio cases had decreased overall by 2011, this decrease was offset by the hundreds of thousands of cases of measles reported the following year (Akhtar et al., 2013). The low rate of immunization was the main cause for this epidemic, and points to the EPI's limited outreach in routine immunization coverage. Among the crucial barriers to successful routine immunization areas are low demand and social resistance to vaccines by certain groups.

Pakistan also has a long history of TB prevalence-responsible for 5.1 percent of the national burden of disease (World Bank, 2010). The 
government's National Tuberculosis Control Program has initiated advocacy and social mobilization, and coordinated with other national healthcare programs such as the Lady Health Workers Program at the community level. This makes it easier to identify cases of TB. Additionally, the National Nutrition Program uses the TB control program to provide micronutrients to TB patients (World Bank, 2010). However, the country still lags behind in achieving the global target of TB case detection of 70 percent (Khan, 2012).

Under the Family Planning and Primary Healthcare Program, the Lady Health Worker Program had recruited more than 103,000 lady health workers (LHWs) by March 2012. Around 76 percent of the target population is now covered by LHWs (Khan, 2012), which has accelerated routine immunization for children across the country and brought about some improvement in antenatal care, contraceptive prevalence, and skilled birth attendance in the areas covered. LHWs are trained primarily at basic health units (BHUs), to which they also refer their clients. However, absenteeism and an inadequate supply of medicines at the BHUs mean that many patients are still denied both preventive and curative treatment. The quality of services delivered by the LHWs also requires regular monitoring and evaluation-processes that are yet to be strictly implemented.

\section{Health Financing}

Political commitment to improving healthcare can be gauged by the budgetary allocations for social sectors. The current level of expenditurePRs 62 billion or 0.35 percent of GDP in 2012/13 - clearly implies that basic public health goods such as health facilities, medicines and supplies, and universal immunization are in short supply. In addition, the share of health expenditure as a percentage of GDP has declined in the past decade from 0.72 percent in $2000 / 01$ to 0.27 in 2011/12 (Khan, 2012). It is, therefore, not surprising that public expenditure on health in Pakistan is less than that in India, Bangladesh, Sri Lanka, and Nepal (World Bank, 2012).

WHO has recommended allocating 6 percent of GDP to curtail the country's deteriorating health conditions. According to the National Health Accounts for 2005/06, Pakistan spent around USD 20 per capita on health, which is far less than what other low-incomes countries spent (around USD 32 per capita) (Pakistan Institute of Legislative Development and Transparency, 2013). The total expenditure on health is about 2.4 percent of GDP, of which private expenditure constitutes 83.6 percent (WHO, 2009). Private expenditure on health as a proportion of 
total health expenditure is far greater in Pakistan than in other South Asian countries. ${ }^{1}$ Moreover, out-of-pocket expenditure as a percentage of private expenditure on health is about 98 percent, positioning Pakistan among those countries with the highest share of out-of-pocket payments relative to total health expenditure (WHO, 2009).

Apart from the low level of expenditure on health, the nature of this expenditure is also disconcerting. According to Islam (2002), Pakistan spent about 85 percent of its healthcare budget on tertiary healthcare, which is utilized by 15 percent of the population. While there has been some improvement in this mix, the regressive nature of public spending persists. Given the increasing burden of communicable disease, the budgetary share of preventive measure programs should also increase.

In recent years, the federal government has taken some positive steps by initiating several vertical programs such as the National Maternal and Child Health Program, the Cancer Treatment Program, and the HIV/AIDS Control Program. Public expenditure on preventive measures and health facilities is progressive at the provincial and regional level, but fails to provide sufficiently at the rural level (Akram \& Khan, 2007).

With the promulgation of the $18^{\text {th }}$ Constitutional Amendment and the 7th National Finance Commission Award, health has now become a provincial subject. The provinces' newly empowered status renders huge responsibilities in terms of formulating policy, streamlining functions, raising funds, and ensuring that existing facilities run smoothly. The National Health Policy of 2009 is no longer relevant in light of the organizational reforms post-2010. At present, there is no national health policy to guide the provinces. While they are expected to develop their own policies, they will still need guidance from the center, especially the smaller provinces, and Pakistan will still require a coherent national agenda for health.

Sharing national health information, financial forecasting, and donor coordination is vital, and in the absence of a federal regulatory authority, an umbrella institution at the federal level could provide a platform for the provinces to work together (Shaikh, 2013). The increased provincial responsibilities require enhanced institutional and management capacities, which are lacking at the moment. The provinces not only need to formulate their own health agendas, they also require skillful execution

\footnotetext{
${ }^{1}$ India, Bangladesh, Nepal, and Sri Lanka.
} 
of these policies and sensitive monitoring systems to gauge performance. While the federal government will continue to run the vertical programs till June 2013, they will eventually have to be taken over by the provinces, and the efficacy of these programs may be threatened by this transition.

\section{Areas of Reform and Conclusion}

Given the current situation, there is much that needs to be done, possibly in every domain of the health sector. Women and children still have the most to lose. There is a dire need for aggressive intervention to strengthen the network of health services, expand the outreach of health programs, and introduce technologies to better monitor and strengthen the health programs in place.

It is imperative for the government to tackle the country's abysmal child and maternal health indicators. Maternal mortality needs to be addressed carefully by increasing the number of skilled health service providers such as female doctors and LHWs in rural areas. These workers should also focus on disseminating awareness of family planning services and supplies.

There is evidence that, apart from low nutritional intake, communicable diseases are also largely responsible for malnutrition in children. In addition to programs such as the EPI, preventive information on healthy practices such as washing hands, treating drinking water, and sanitation should be systematically disseminated. It is estimated that 4 billion cases of diarrhea each year, mostly in developing countries, cause at least 1.8 million deaths, of which 90 percent are children under the age of five (United Nations Children's Fund, 2008). About 88 percent of these deaths are attributable to unsafe water supply, inadequate sanitation, and poor hygiene (WHO, 2005).

In this regard, the private sector and NGOs could play a crucial role in spreading awareness among schools, colleges, and universities. In 2009, the private multinational Procter \& Gamble Pakistan and the NGO Save the Children came together to build 100 sanitation facilities in 100 days across Karachi, Lahore, and Quetta. They targeted 40,000 school-age children in their health and hygiene awareness campaign. ${ }^{2}$ Such measures could help reduce the burden of communicable disease to a large extent.

\footnotetext{
${ }^{2}$ For more information, on Procter \& Gamble Pakistan's new partnership to reach 100 primary schools in Pakistan through a school health project, see http://www.pg.com/en_PK/news/sagfeguard_build_ sanitation_facilities.shtml
} 
However, this does not shed the public sector's responsibility, which has the most to contribute in terms of improving the country's water and sanitation sector. Public-private partnerships need to be encouraged in tackling health issues.

Addressing the issue of noncommunicable diseases is equally important for the adult population. Given the loss of healthy life years caused by these diseases, the government needs to incorporate programs at the BHU level to effectively prevent the spread of such diseases. Moreover, in order to accurately determine and analyze the burden of disease, a cause-of-death system that collects detailed information on disease prevalence and mortality should be put in place (Hyder \& Morrow, 2000). The healthcare system must cater to the twin burden of communicable and noncommunicable diseases simultaneously, which again necessitates public-private support in health financing.

This leads us to the issue of health expenditure in Pakistan. With one of the lowest public expenditure shares on health, the government needs to make an effort to mobilize more resources. While out-of-pocket expenditure on free health services is growing enormously, approximately 4 percent of the population falls into poverty due to health shocks each year. This risk is even higher in rural areas - the highest being in $\mathrm{KP}$ - and increases with household size and lower income levels (World Bank, 2010).

Improved monitoring and evaluation is also necessary not only to improve the performance of the health sector but also to enhance existing programs and reforms. Some instruments, such as the Health Monitoring Information System developed by the government in 1992 with the help of USAID, are in place, but the public health surveillance system in Pakistan is still fragmented and has been unable to generate the data required to make informed public health decisions. ${ }^{3}$ Callen, Gulzar, Hasanain, and Khan (2013) draw on the admirable example of an intervention conducted at the BHU level to monitor public worker absenteeism. They use smartphone technology designed to increase inspections at rural clinics, which proved practical for their purposes. Such studies can be useful in developing effective means of monitoring and evaluating the health system.

\footnotetext{
${ }^{3}$ In an effort to improve monitoring, the Ministry of Health (prior to the 18th Amendment) designed a district health information system that covers the hospital sector in addition to primary health facilities. The Japan International Cooperation Agency (JICA) has provided technical expertise and aid for the project. The system has already been tested in pilot districts and the plan is to expand it across Pakistan. This is still an ongoing project (See http://www.jica.go.jp/pakistan/english/activities/activity02_03.html).
} 
Social protection in the form of health insurance could also play a critical role in protecting against health shocks, although the idea has limited scope in Pakistan. In KP, bilateral agencies have promoted social health insurance with support from the religious community, capitalizing on its nonprofit solidarity characteristics. This has served as a call to policymakers for future action. The federal and Punjab governments have also assessed the prospect of health insurance but no plans have been implemented. Needless to say, there is minimal linkage between Pakistan's social protection strategy and the health sector (Nishtar, 2010). In its budget for 2009/10, the government announced that the Benazir Income Support Program would cover health insurance, implying that it was a program only for the ultra-poor (World Bank, 2011). Most evaluations of the program are, however, cautiously optimistic.

We can analyze alternative means of health financing by looking at the health sector across the border in India. The Rajiv Aarogyasri Health Insurance Scheme is an example of one such successful program implemented in Andhra Pradesh. It has successfully covered 87 percent of families living below the poverty line, even though it only covers medical conditions that pertain to catastrophic illnesses (Yellaiah, 2013). The scheme has also substantially reduced out-of-pocket expenditure per capita in the state. On the downside, disease prevention is relegated to the background under such publicly funded insurance schemes, while hospitalization is seen to be a one-off solution to ill health (Karan \& Selvaraj, 2012). Despite the pros and cons of such state-funded localized health insurance schemes, an ideal policy would target universal health coverage, providing a push from primary healthcare-level upward.

Following the promulgation of the 18th Amendment to the Constitution, provincial and local governments in Pakistan are constrained by a lack of expertise in formulating pertinent health policies and inadequate institutional capacity to carry out reforms. What the country needs at this point is a focused multi-pronged approach that will improve the provision of primary and tertiary healthcare by building on existing infrastructure and expanding services into areas with limited outreach. With more funds allocated to health, a system of monitoring should be in place to ensure that public resources are properly utilized. Once a universal health policy is formulated, the private sector can better identify its role in complementing that of the state in health service provision. 


\section{References}

Akhtar, T., Bengali, K., Bhutta, Z. A., Ghaffar, A., Asmat Isa, Q., Jafar, T. H., Rahim, E. (2013). Health reform in Pakistan: A call to action. The Lancet, 381(9885), 2291-2297.

Akram, M., \& Khan, F. J. (2007). Healthcare services and government spending in Pakistan (Working Paper No. 2007-32). Islamabad, Pakistan: Pakistan Institute of Development Economics.

Callen, M., Gulzar, S., Hasanain, A., \& Khan, Y. (2013). The political economy of public employee absence: Experimental evidence from Pakistan. Unpublished manuscript. Retrieved from http:/ / econ.ucsd.edu/ mjcallen/pdfs / pea.pdf

Healthcare: The measles muddle. (2013, January 20). Dawn. Retrieved from http:/ / beta.dawn.com/news/780134/health-care-the-measlesmuddle

Hyder, A. A., \& Morrow, R. H. (2000). Applying the burden of disease methods in developing countries: A case study from Pakistan. American Journal of Public Health, 90(8), 1235-1240.

Hyder, A. A., Wali, S. A., Ghaffar, A., Masud, T. I., \& Hill, K. (2005). Measuring the burden of premature mortality in Pakistan: Use of sentinel surveillance systems. Public Health, 119(6), 459-465.

Islam, A. (2002). Health sector reform in Pakistan: Future directions. Journal of Pakistan Medical Association, 52(4), 174-182.

Karan, A. K., \& Selvaraj, S. (2012). Why publicly financed health insurance schemes are ineffective in providing financial risk protection. Economic and Political Weekly, March 17.

Khan, A. (2012). Health and nutrition. In Pakistan economic survey 2010-11. Islamabad, Pakistan: Finance Division.

Khan, A. (2013). Health and nutrition. In Pakistan economic survey 2012-13. Islamabad, Pakistan: Finance Division.

Millennium Project. (2006). Why the Goals are important [Webpage]. Retrieved from http:/ / www.unmillenniumproject.org/reports/why.htm 
Nishtar, S. (2010). Choked pipes: Reforming Pakistan's mixed health system. Karachi, Pakistan: Oxford University Press.

Pakistan Bureau of Statistics. (2011). Pakistan social and living standards measurement survey 2010-11 (chap. 3). Islamabad, Pakistan: Author. Retrieved from http://www.pbs.gov.pk/sites/default/files/ pslm/publications/pslm_prov2010-11/health.pdf

Pakistan has the 8th highest newborn mortality rate. (2010, January 10). Daily Times. Retrieved from http://www.dailytimes.com.pk/default.asp? page $=2010 \% 5$ C01\%5C20\%5Cstory_20-1-2010_pg12_11

Pakistan Institute of Legislative Development and Transparency. (2013). Understanding Punjab health budget 2012-2013: A brief for standing committee on health, Provincial Assembly of the Punjab. Lahore, Pakistan: Author.

Pakistan, Planning Commission. (2010). Pakistan Millennium Development Goals report 2010: Development amidst crisis. Islamabad, Pakistan: Author.

Pakistan Poverty Alleviation Fund. (2010). Cost-effective quality healthcare: Unraveling the paradox. Islamabad, Pakistan: PPAF Media and Communication Unit.

Procter \& Gamble, Pakistan. (2009). Safeguard and save the children to build sanitation facilities in 100 schools in Pakistan in 100 days [Press release]. Retrieved from http://www.pg.com/en_PK/news/sagfeguard_ build_sanitation_facilities.shtml

Punjab, Planning and Development Department, \& United Nations Development Programme. (2011). Punjab Millennium Development Goals: Report 2011. Lahore, Pakistan: Authors.

Shaikh, B. (2013). Devolution in health sector: Challenges and opportunities for evidence-based policies [PowerPoint presentation]. Retrieved from http:/ / www.lead.org.pk/ow / attachments/stakeholder_dialogue /14december/Devloution\%20in\%20Health\%20Sector\%20by\%20D r.\%20Babar\%20Tasneem.ppt 
United Nations Children's Fund. (2008). UNICEF handbook on water quality. New York, NY: Author. Retrieved from http://www.unicef.org/wash/files/WQ_Handbook_final_signed _16_April_2008.pdf

World Bank. (2010). Delivering better health services to Pakistan's poor (Report No. 68258). Washington, DC: Author.

World Bank. (2011). Social protection in health: What are the options for Pakistan? (Pakistan Social Protection Policy Note No. 64406). Washington, DC: Author.

World Bank. (2012). World development indicators 2012. Retrieved from data.worldbank.org

World Health Organization. (2005). The world health report: Make every mother and child count. Geneva, Switzerland: Author. Retrieved from www.who.int/whr/2005/en/

World Health Organization. (2009). World health statistics (pp. 107-117). Geneva, Switzerland: Author. Retrieved from http://www.who.int/whosis/whostat/EN_WHS09_Table7.pdf

World Health Organization. (2013). Data and statistics [Webpage]. Retrieved from http://www.who.int/research/en/

World Health Organization, Pakistan, Ministry of Health, \& Heartfile. (2004). National action plan for prevention and control of noncommunicable diseases and health promotion in Pakistan. Islamabad, Pakistan: Authors.

Yellaiah, J. (2013). Health insurance in India: Rajiv Aarogyasri health insurance scheme in Andhra Pradesh. IOSR Journal of Humanities and Social Science, 8(1), 7-14. 